\title{
A ESCOLA NA BERLINDA: PESQUISA DOCUMENTAL E NARRATIVAS JUVENIS EM FOCO
}

\author{
THE SCHOOL IN THE SPOTLIGHT: DOCUMENTARY RESEARCH AND JUVENILES \\ NARRATIVES IN FOCUS
}

\section{LA ESCUELA EN EL BANQUILLO: INVESTIGACIÓN DOCUMENTAL Y NARRATIVAS JUVENILES ENFOQUE}

\author{
Eduardo Antonio de Pontes Costa \\ Universidade Federal da Paraíba - Brasil \\ Rosângela Lopes da Silva \\ Universidade Federal da Paraíba - Brasil
}

\begin{abstract}
Resumo: Este estudo propõe discutir o lugar que a escola ocupa na vida dos jovens matriculados nas turmas da Educação de Jovens e Adultos (EJA). Trata-se de um estudo de caso realizado numa escola da rede municipal de Cabedelo, Paraíba. O Diário de Classe e a ficha-individual referentes aos anos de 2017 e 2018 bem como entrevista semi-estruturada, realizada com os alunos dos Ciclos III e IV da EJA, respaldam o trabalho empírico. Alguns resultados indicam que eles vão para as turmas da EJA, ou a isso são "obrigados", frente à retenção e evasão escolar promovidas pela Escola. Os dados do Ciclo III, Turmas A e B, ano 2017 e a Turma "Única", ano 2018, referidos ao desempenho escolar, a partir dos saberes de Português, Matemática, Geografia, Ciências, História, Inglês e Artes, apontam que, dos 112 alunos, a média é de 34 alunos aprovados. E os do Ciclo IV, contemplando os mesmos saberes, mostram uma média de 46,14 de aprovados, de 79 alunos matriculados nos anos 2017 e 2018 . Conciliar escola e trabalho, experimentar turmas heterogêneas e apresentar baixo rendimento escolar são variáveis concretas que apontam para a complexidade dessas histórias escolares assimétricas, reativadas por trajetórias descontínuas na Educação Básica. As fontes documentais e as narrativas dos jovens mostram que o problema histórico da retenção e da evasão escolar é também o fracasso da escola, ao contribuir, especificamente, para os processos de exclusão e de desigualdades sociais.
\end{abstract}

Palavras-chave: Jovens. Pesquisa documental. Trajetória escolar.

Abstract: This study proposes to discuss the place that the school occupies in the lives of young people enrolled in the Youth and Adult Education (EJA) classes. This is a case study carried out at a school in the municipal network of Cabedelo, Paraíba. The individual form and the Class Diary for the years 2017 and 2018, as well as a semi-structured interview with the students of Cycles III and IV of the EJA support the empirical work. The results indicate that they go to the EJA classes, or are "obliged" to do so, due to the production of retention and school dropout promoted by the school. Data from Cycle III, Classes A and B, from 2017 and the Class "Única", year 2018, referring to school performance, based on the knowledge of Portuguese, Mathematics, Geography, Sciences, History, English and Arts, point out that, of the 112 students, the average is 34 approved 
students. And those from Cycle IV, considering the same knowledge, show an average of 46.14 approved, of 79 students enrolled in the years 2017 and 2018. Reconciling school and work, experimenting with heterogeneous classes and showing low school performance are concrete variables that point to the complexity of these asymmetric, school histories reactivated by discontinuous trajectories in Basic Education. Documentary sources and young people's narratives show that the historical problem of school retention and dropout is also the failure of the school to contribute, specifically, to the processes of exclusion and social inequality.

Keywords: Youths. Documentary research. School trajectory.

Resumen: Este estudio propone discutir el lugar que ocupa la escuela en la vida de los jóvenes inscritos en las clases de Educación de Jóvenes y Adultos (EJA). Es un estudio de caso realizado en una escuela de la Rede Municipal de Cabedelo, Paraíba. El diario de clase y el archivo individual que hace referencia a los años 2017 y 2018, así como una entrevista semiestructurada, realizada con los estudiantes de los ciclos III y IV de EJA, respaldan el trabajo empírico. Algunos resultados indican que van a las clases de EJA, o están "obligados" a hacerlo, en vista de la retención y el abandono escolar promovidos por la escuela. Los datos del Ciclo III, Clases A y B, año 2017 y la Clase "Única", año 2018, que se refieren al rendimiento escolar, basados en el conocimiento de portugués, matemáticas, geografía, ciencias, historia, inglés y artes, señalan que, de los 112 estudiantes, el promedio es de 34 estudiantes aprobados. $\mathrm{Y}$ aquellos en el Ciclo IV, considerando el mismo conocimiento, muestran un promedio de 46.14 aprobados, de 79 estudiantes matriculados en los años 2017 y 2018. Conciliar la escuela y el trabajo, experimentar con clases heterogéneas y mostrar bajo rendimiento escolar son variables concretas que apuntan a La complejidad de estas historias escolares asimétricas, reactivadas por trayectorias discontinuas en Educación Básica. Fuentes documentales y narrativas juveniles muestran que el problema histórico de la retención y el abandono escolar es también el fracaso de la escuela, ya que contribuye específicamente a los procesos de exclusión social y desigualdad.

Palabras clave: Jóvenes. Investigación documental. Trayectoria escolar.

\section{Introdução}

Hoje, no Brasil, as tentativas de democratização do acesso à escola pública são bem visíveis. As estatísticas oficiais apontam para o aumento do número de matrículas nas redes de ensino. No campo das políticas públicas, as parcerias entre União, Estados e Municípios implementam ações, programas e projetos, buscando garantir o acesso do estudante aos espaços escolares e sua permanência ali. Tais esforços governamentais representam avanços expressivos na garantia da universalização do direito à educação (PAIVA, 2016; HADDAD, 2017).

Por outro lado, o caráter dessa "universalização" depara-se com desafios ainda estruturais na história da educação brasileira que não permitem avançar na oferta do direito à educação como um direito público subjetivo, inscrito na Constituição Federal (CF) de 1988. Há um nítido contraste entre as falas dos estudantes, os documentos oficiais da escola investigada e os documentos oficiais que garantem o direito à escolarização. Para falarmos de que toda política pública se afirma pelo "ideal da igualdade de oportunidades", como 
sublinha Paiva (2016), a democratização do acesso à escola ainda se dá nas desigualdades de ascensão escolar e profissional. O aumento do número de matrículas e os resultados nos processos de escolarização não correspondem ainda, contudo, na melhoria do indicador qualidade na educação básica, uma vez que a expansão dos sistemas de ensino se deu de forma não homogênea. É o que podemos observar nos estudos de Grosbaum e Falsarella (2016, p. 300) os quais identificam, no contexto da escola, que a expansão do ensino médio se dá por assimetrias e que outras questões se avolumam diante "[...] da alta porcentagem de jovens ainda fora da escola e a persistência dos altos índices de evasão, abandono e reprovação". Neste sentido, parece-nos que estamos diante de práticas educativas "dissonantes" quando há indícios de que os sistemas de ensino buscam proporcionar a universalização do acesso à escola, secundarizando variáveis vitais para a promoção de espaços escolares mais qualificados, como questões relativas: a) a uma proposta curricular integrada à realidade social e cultural dos alunos; b) à aprendizagem, respeitando-se a dimensão social e cultural do conhecimento e em sintonia com as competências requeridas para os três níveis de ensino; c) ao reconhecimento da escola pública democrática e cidadã; d) à valorização da carreira docente para a educação básica etc.

A conjunção desses e outros elementos reafirmam o problema para a garantia da permanência nos espaços escolares e pode responder pelo sucesso do ensino e pela aprendizagem dos alunos nos processos de escolarização, sobretudo quando consideramos que a “[...] escola pública acolhe hoje a quase totalidade das crianças dos bairros pobres, mas começa cedo a perdê-las, já na pré-adolescência”, como destaca Fernandes (2004, p. 262).

No tocante às ações públicas, sabemos que elas apresentam, certamente, avanços, pois há sistemas de ensino comprometidos com o que preconizam a Constituição Federal e a Lei de Diretrizes e Bases da Educação Básica (LDB), Lei 9394 de 1996. Por outro lado, e em relação aos alunos e à criação de espaços potentes de aprendizagem, parece-nos que algumas realidades escolares não incorporam ao seu saber-fazer pedagógico o saber das crianças e dos jovens. E esta realidade, portanto, vai contribuindo para imobilismos e paradoxos, como os relacionados ao fracasso escolar, oriundo das práticas escolares de retenção e reprovação dos alunos considerados "inadequados", tendo em vista alguns comportamentos concebidos como antissociais pela escola etc. Aqui temos, na perspectiva seletiva da escola, o "[...] menosprezo às diferenças individuais apenas para eliminar os reputados incapazes", como costumava avaliar Anísio Teixeira (1977, p. 389). Neste contexto, a escola, não conseguindo contribuir para superar estes paradoxos, passa a 
legitimar uma realidade constitutiva que nos direciona para a difícil equação do direito à igualdade para os alunos das classes populares (DAYRELL, 2007; PAIVA, 2016; GROSBAUM; FALSARELLA, 2016).

Com base nessas considerações, este artigo é o resultado de uma pesquisa que buscou compreender o lugar que a escola pública ocupa na vida dos jovens com histórico de retenção no Ensino Fundamental e de evasão nas turmas da EJA. Ele está dividido em quatro momentos analíticos. O primeiro tece, com base na revisão bibliográfica, algumas reflexões sobre a categoria juventude, a condição juvenil, os processos de escolarização e suas desigualdades. O segundo momento apresenta a metodologia do estudo, baseada em entrevista semiestruturada, com jovens matriculados nos Ciclos III e IV da EJA, assim como a pesquisa documental, tomando como analisadores o Diário de Classe e a Ficha Individual do Aluno, com foco nos anos de 2017 e 2018. O terceiro momento apresenta análises sobre os achados dos Diários de Classe e da Ficha Individual sobre a trajetória escolar dos jovens. Por este caminho, intercalam-se as narrativas juvenis sobre suas experiências escolares, o que eles pensam do mundo do trabalho e os seus projetos profissionais. Por fim, nas considerações finais, são retomadas/discutidas algumas questões relativas à escola investigada - percebida como um espaço "distante" para os jovens - e aos efeitos das práticas de retenção e de evasão que marcam e definem as trajetórias descontínuas desses sujeitos ao proporcionar formas desiguais de acesso à escolaridade na idade/ano escolar regular.

\section{Juventude e escola}

São tênues as fronteiras entre adolescência e juventude. Elas possuem limites variados em função de parâmetros socioculturais e em função, também, dos tratamentos estatísticos assumidos pelas instituições que analisam ou apresentam programas e projetos junto a este segmento populacional. Para investigações que tematizam a juventude, algumas a definem como uma categoria essencialmente sociológica, que indica para o processo de preparação do indivíduo para assumir o papel de adulto na sociedade, tanto no plano familiar quanto no profissional (WAISELFISZ, 2011).

Tematizada pela Sociologia como categoria analítica e, ao assumir novas formas de socialização diante da complexa dinâmica da sociedade, juventude é:

[...] uma categoria socialmente construída e ganha contornos próprios em contextos históricos, sociais e culturais distintos, marcada pela diversidade nas condições sociais (origem de classe, por exemplo), culturais (etnias, identidades religiosas, valores, [sic] etc.), de gênero e, [sic] até mesmo 
geográficas, dentre outros aspectos (DAYRELL; NOGUEIRA; MIRANDA, 2011, p. 14).

Trata-se de contextos históricos e sociais que constituem parâmetros desafiadores diante de novas incertezas, sobretudo para os jovens que experimentam e buscam produzir redes de pertencimento no contexto de um capitalismo subjetivo, em espaços sociais cada vez mais contraditórios, seja em função do acesso ao conhecimento, da competitividade, seja em função da capacidade de resolução de novos problemas, quando os jovens têm, certamente, que "extrair o melhor de si e se autoaperfeiçoar" (BAUMAN, 2013, p. 47).

A noção de juventude que perpassa este trabalho nos permite falar não a partir de uma noção monolítica, homogênea, mas de uma juventude diversa, plural, traduzida na multiplicidade de sujeitos, de rostos, de falas e de lugares, pois, contemporaneamente, a juventude "[...] não é mais somente uma condição biológica mas uma definição cultural. Incerteza, mobilidade, transitoriedade, abertura para mudança de todos os atributos tradicionais da adolescência como fase de transição [...]” (MELUCCI, 1997, p. 9).

No cenário brasileiro, Dayrell (2007, p. 1107) nos fornece subsídios consistentes para uma compreensão mais ampla, em especial sobre a relação da juventude com a escola. E uma primeira constatação de sua análise aponta-nos para a "existência de uma nova condição juvenil”. Essa discussão assume papel central na análise do referido autor, apresentando questões contundentes sobre o jovem matriculado nas redes públicas de ensino. E com suas demandas singulares, ele traz para a "cena escolar" especificidades e linguagens próprias de um contexto que se distingue de uma certa ordem moral e simbólica de gerações anteriores.

Reflexo disso é a positividade da noção de "condição juvenil", que diz respeito ao modo como a sociedade produz sentidos e significações a esta fase da vida, "[...] no contexto de uma dimensão histórico-geracional, mas também à sua situação, ou seja, o modo como tal condição é vivida a partir dos diversos recortes referidos às diferenças sociais - classe, gênero, etnia etc.” (DAYRELL, 2007, p. 1108).

Sobre a percepção dos jovens em relação à escola e ao trabalho, Castro (2004, p. 296) mostra, na sua pesquisa, entre outros aspectos, dados preocupantes em relação aos jovens que trabalham e aos que não trabalham. De forma progressiva, a escola é logo abandonada pelo jovem, caso apareça uma oportunidade de trabalho, não importando se a atividade laboral seja no subemprego ou informalidade.

Estudos sobre acesso e permanência na escola pública revelam que os esforços concentrados na universalização do Ensino Fundamental não promovem impactos positivos na qualidade do ensino. Alunos que concluem a primeira fase do Ensino Fundamental não dominam leitura, escrita e cálculo e, quando matriculados na segunda fase, permanecem em 
sala de aula. Contrariando o que preconizam marcos legais na garantia do direito à educação para crianças e adolescentes, aqueles considerados "incapazes" pelo sistema de ensino, reflexo das desigualdades produzidas em sala de aula, tornam-se precocemente os sujeitos da Educação de Jovens e Adultos.

Por essa perspectiva, a juvenilização - denominada de grupo intergeracional (CONCEIÇÃO, 2015) - passa a ser um desafio a mais para a modalidade da EJA, como assinalam Oliveira e Costa (2020). E somadas às questões de diferentes matizes que atravessam a escola pública e aos efeitos da falta de integração desses espaços para os alunos do ensino regular, esse cenário demanda investigações e análises, na tentativa de compreendermos quais fatores produzem o que Sodré (2012, p. 246), ao refletir sobre a relação da juventude com o ensino médio, irá caracterizar como “[...] a fraca democratização do ensino, que deveria definirse pela igualdade das condições de permanência na escola e de progressão satisfatória. [...]”. Dito de outra forma, ser compulsoriamente retido no Ensino Fundamental regular e encaminhado às turmas da EJA é um dos efeitos danosos para as crianças e jovens quando experimentam "um tênue vestígio da democratização do saber".

Essas tensões e contradições revelam que as questões do acesso à educação básica e permanência do aluno vão muito além dos dados oficiais, dos dados estatísticos. Como nos esclarece Dayrell (2007, p. 1106): "Um primeiro passo é constatar que a relação da juventude com a escola não se explica em si mesma: o problema não se reduz nem apenas aos jovens, nem apenas à escola". Numa perspectiva mais ampla, trata-se, muito provavelmente, de tensionar não apenas as políticas educacionais em curso alinhadas às transformações, excludentes frente às novas tecnologias, advindas do mundo do trabalho, cada vez mais exigente do ponto de vista do trabalhador - as competências e habilidades requeridas - mas também perguntar a quais prioridades a escola pode responder diante de espaços presenciais ou virtuais que "[...] vão se mesclando aos modos tradicionais de ensinar, aprender, avaliar e gerir as escolas, não sem polêmicas e sobressaltos causados aos seus profissionais" (GROSBAUM; FALSARELLA, 2016, p. 297).

Com base no que é socialmente conferido aos jovens em diferentes contextos sociais e culturais, realizamos nossa pesquisa direcionada aos jovens "desfocadamente visíveis" (ABRAMO, 1997), os dos setores populares, os que comprometem a "taxa de escolarização líquida", e que enfrentam trajetórias escolares fragmentadas (DAYRELL; NOGUEIRA; MIRANDA, 2011; TEIXEIRA, 2018). 


\section{Pistas investigativas e o encontro com a escola noturna}

A compreensão e a complexidade do trabalho acadêmico na formação de professores que irão atuar na Educação Básica reafirmam a importância de diálogos sempre profícuos e problematizadores na produção de novos saberes junto aos alunos. O processo de ensino e aprendizagem abarca, portanto, questões que não dizem respeito apenas às metodologias e à produção do conhecimento. Ele demanda articulações e encontros reflexivos e questionadores sobre o que estamos fazendo a partir das nossas práticas pedagógicas. Neste sentido, e apesar dos avanços e retrocessos no campo da formação para o magistério, as disciplinas de formação docente que integram quali-quantitativamente teoria e prática, atentam para a importância de se pensar não apenas a formação inicial, no seu sentido strictu sensu, mas as interlocuções conceituais e institucionais que, numa relação de simultaneidade entre ação/reflexão/ação, proporcionam, muito provavelmente, um "olhar" mais próximo sobre o cotidiano, em especial, de uma escola pública.

Por essa via, a seleção da escola da rede municipal de Cabedelo, uma das cidades que compõem a Região Metropolitana de João Pessoa, se deu por ter sido o ambiente (ou campo de atuação) onde se realizaram - por parte dos alunos do curso de Licenciatura em Pedagogia da Universidade Federal da Paraíba (UFPB) - atividades oriundas dos Componentes Curriculares Estágio Supervisionado III e IV, respectivamente Ensino Fundamental e Educação de Jovens e Adultos, em que a problemática da retenção e da evasão escolar era flagrante.

Pela perspectiva da formação docente, o componente curricular obrigatório Trabalho de Conclusão de Curso (TCC) representa um tempo e um espaço de oportunidades quando consideramos importante produzir questões sobre os sujeitos da educação e sobre nós mesmos - sujeito/objeto na produção de diferentes saberes. É importante destacar que as nossas inquietações sobre o problema da retenção e da evasão identificadas nas turmas da EJA, e iniciadas em 2018, foram fundamentais para a definição do problema que iria definir o projeto de TCC, na área de aprofundamento Educação de Jovens e Adultos. E foi a partir de embates de permanente tensão que buscávamos pensar e definir que alunos poderiam participar da pesquisa. A escolha da amostra se deu, portanto, em função de os jovens entrevistados serem os alunos mais frequentadores da escola, matriculados nos Ciclos III e IV do Ensino Fundamental da EJA; além disso, contribuiu para tal escolha o fato de esses alunos comporem o universo dos sujeitos da retenção escolar, no Ensino Fundamental, e da evasão, nas turmas da educação de adultos, com idades compreendidas entre 15 e 18 anos.

Em março de 2019, e após a autorização da Direção da Escola para a qual os propósitos da investigação foram colocados, passamos a conversar informalmente com os alunos das duas 
turmas referidas sobre a possibilidade de eles participarem da pesquisa. Algumas variáveis passaram a dificultar o contato com os possíveis entrevistados - infrequência era a mais determinante como desafio; outra, talvez de menor impacto, dizia respeito ao tempo da entrevista. Tínhamos menos de uma hora para realizá-la. As aulas eram iniciadas às $19 \mathrm{~h}$, e, quando os jovens chegavam à escola, mesmo diante da agenda prévia com eles, tínhamos apenas meia hora para a realização da entrevista. Outra variável era ficarmos atentos à temporalidade dos jovens, ou seja, aqueles que chegavam mais cedo, iam dividir seu tempo com os colegas da turma, partilhar conversas, "trocar ideias", pelo pátio da escola, acessar seus equipamentos eletrônicos, "modular" uma possível "DR" (discutir relação) etc. Era nessa perspectiva que buscávamos privilegiar, sem dúvida, os jovens na sua travessia pela escola, buscando identificar o lugar que ela ocupava em seus projetos de vida.

É importante acrescentar que os jovens desta pesquisa foram alunos de uma mesma Instituição, que não encontraram o devido acolhimento no ensino sequencial regular e foram conduzidos pelo próprio sistema de ensino - e com consentimento do responsável - à turma da EJA ou pelo retorno do jovem à tentativa de conclusão do Ensino Fundamental. O "consentimento" citado se refere a uma "manobra" da gestão escolar que propõe aos pais ou responsáveis a condução do seu tutelado com baixo rendimento escolar, logo considerado "inadequado", à turma da educação de adultos quando ele atinge a idade mínima, 15 anos completos, para o ingresso nos cursos da EJA, no Ensino Fundamental. Proposta semelhante é feita ao aluno que completa 18 anos, fazendo-o migrar para o Ensino Médio. Ambas as propostas são regidas pela Resolução $\mathrm{CNE} / \mathrm{CEB} \mathrm{n}^{\circ} 3$, de 2010, artigo $5^{\circ}$.

Depois de apresentados e explicados os objetivos da pesquisa, as entrevistas, com a prévia autorização da Direção da Escola, foram realizadas na sala de aula, com a permissão dos alunos entrevistados e com a assinatura do Termo de Consentimento Livre e Esclarecido (TCLE) pelo jovem maior de 18 anos e/ou pelos pais/responsáveis para os que apresentavam dezoito anos incompletos. Todas as falas foram transcritas na íntegra. Lidas e relidas, inclusive, com retorno para as entrevistas que demandavam informações complementares.

Vale ressaltar que, ao longo das entrevistas, observamos que as conversas "com intenção" pareciam não fluir com os jovens. Talvez seja uma dificuldade dos pesquisadores diante do tempo burocrático da pesquisa e até mesmo dos "laços de confiança" que não foram produzidos na relação com os jovens. Chegamos lá para coletar informações junto a eles. O caminho inverso ainda não fizemos, no sentido de pensar junto com eles o contexto concreto do ambiente local em suas trajetórias escolares. 


\section{A relação entre a escola e os jovens}

Hoje, certamente, outros riscos são colocados para a escola e para os jovens diante das mudanças que ocorrem no mundo do trabalho, seja através das novas tecnologias, das novas formas de precarização de suas relações, ou das novas demandas em termos de qualificação profissional. Desse modo, as questões, especificamente as da escola, agora se voltam para a sua competência no sentido de contribuir, sem dúvida, para a produção de novos conhecimentos e habilidades. Nessa perspectiva, e considerando o saber-fazer pedagógico e o conhecimento do saber específico dos alunos, “A entrada na vida adulta é, para os jovens, resultado de uma série de aprendizagens para as quais a escola contribui de modo ambíguo, uma vez que depende do currículo, da gestão da escola, do comprometimento docente e das condições estruturais do sistema" (GROSBAUM; FALSARELLA, 2016, p. 297).

Essa realidade, apontada por Grosbaum e Falsarella (2016) e que pode trazer importantes efeitos para a vida adulta dos jovens, expressa, sem dúvida, situações diversas e complexas que revelam, podemos dizer, problemas direcionados à escola - os que chegam de fora para dentro - e os produzidos pela própria escola, como podemos observar a partir dos dados/registros da escola e das falas dos jovens que enunciam e apresentam um claro recorte de classe em termos de sua origem social, da sua cor e do seu local de moradia.

\subsection{O diário de classe e a ficha-individual}

No plano conceitual, partilhamos da compreensão de Gil (2002, p. 46) de que a pesquisa documental deve levar em consideração que os documentos constituem importantes fontes de dados e de informações. Por essa perspectiva, entendemos o Diário de Classe e a Ficha Individual como fontes de pesquisa documental, levando-se em consideração que estes ainda não receberam, como documentos de "primeira mão", nenhuma leitura analítica.

O Diário de Classe e a Ficha Individual, como elementos substanciais na organização do trabalho pedagógico e acrescidos ao aspecto burocrático-administrativo da gestão escolar, não só apresentam/traduzem elementos próprios da dinâmica institucional como também desvelam dados e informações relevantes, normalmente "descurados" pelo caráter meramente técnico-burocrático naturalizado pela gestão escolar e pelo trabalho docente. "Desvelam" no sentido de que se trata de documentos ativados por uma certa engrenagem escolar que funciona como dispositivo pela lógica da regulação social, possibilitando, igualmente, "[...] refletir e contextualizar os aspectos sociais, políticos e até econômicos do período" (CRUZ; MOREIRA, 2016, p. 4). 
Informamos que a análise documental da pesquisa deu ênfase aos ditos dos registros institucionais sobre seus alunos, privilegiando os anos de 2017 e 2018. Informamos, também, que a escolha desse período se deu em função da informatização dos dados, pela escola, a partir de 2017, o que nos garantiu, de certa forma, ter acesso às informações sistematizadas no tocante às categorias de retenção, desistência, aprovação, reprovação, defasagem por idade/série, nas turmas do Ensino Fundamental I e II; e a problemática da evasão e desistência escolar, nas turmas dos Ciclos III e IV da EJA.

E o que dizem os Diários e a Ficha Individual sobre os alunos da EJA? Nas Fichas Individuais dos anos 2017 e 2018, identificamos os seguintes perfis: para o ano de 2017, a Turma A do Ciclo III apresenta 30 alunos, com uma média de idade de 22,76 anos com uma convergência mais predominante de 14 a 29 anos. Do total de 30 alunos, 04 apresentavam idade de 14 anos. Identificamos também alunos entre 30 e 50 anos. Para a Turma B do Ciclo IV, que tem 25 alunos, a média de idade é de 29,52 anos, sendo predominantes jovens entre 15 e 30 anos. Há também adultos e idosos, com idade variando entre 29 e 62 anos. Na turma do Ciclo IV, com 39 alunos, 21,28 é a média de idade. Jovens entre 15 e 35 anos são dominantes. Há também alunos com faixa etária entre 38 e 59 anos.

Ainda neste contexto, para o ano de 2018, a turma "Única" do Ciclo III tem um perfil de alunos com uma média de 27,71 anos de idade. De um total de 57 alunos, 33 encontram-se na faixa etária de 15 a 30 anos de idade. Os demais se encontram na faixa etária de 31 a 63 anos. Na turma do Ciclo IV, a média de idade é de 21,02 anos. A predominância é entre 13 a 25 anos, com 31 alunos. E entre 30 e 59 anos, 06 alunos. Somente 01 aluno tinha 13 anos.

Uma pertinente compreensão, especificamente do plano conceitual no campo do direito à educação, como podemos identificar nos marcos legais que garantem o acesso e à permanência nos espaços escolares, nos permite indagar: $\mathrm{O}$ que esses dados expressam e denunciam? Por que a escola não produz espaços "sedutores", "potentes", para os alunos?

Trata-se, nos parece, de uma dinâmica convergente da instituição, que atravessa uma série de questões estruturais nos espaços escolares, proporciona e legitima a fabricação de trajetórias assimétricas para os seus alunos. Os dados sinalizam que os alunos na faixa etária entre 13 e 14 anos foram conduzidos às turmas da EJA em "acordo" feito, como referido, com a gestão da escola e os pais ou responsáveis. Leituras aproximadas à de Sodré (2012, p. 113) nos permitem dizer que esse encaminhamento compulsório - e dentro da lógica do discurso pedagógico que naturaliza sujeitos e práticas - vai operando "efeitos de adesão", os quais legitimam o não reconhecimento do direito à educação. 
Ao sistematizarmos os registros de retenção, desistência e evasão, os dados concretos são graves e preocupantes. Com base no Diário de Classe e na Ficha Individual do Aluno, a produção dos considerados "incapazes" é aguçada, provavelmente pela falta de ações conjuntas e articuladas, da escola, sobre a realidade social dos seus alunos e também a partir dessa realidade. Quando propomos localizar o aluno no aspecto do desempenho escolar, tanto no ensino fundamental regular quanto nas turmas da EJA, um ponto de interseção os une: a ausência do reconhecimento como sujeitos do direito humano à educação.

- O JovemA17anos foi retido no $3^{\circ}$ ano, em 2010, com média baixa nas disciplinas de Português e História; foi retido no $5^{\circ}$ ano, em 2013, no horário matutino, nessa escola. No $6^{\circ}$ ano, foi retido 2 vezes, nos anos de 2015 e 2016, à tarde; em 2017, foi retido, à noite, no Ciclo III da EJA. E, em 2018, foi desistente do $6^{\circ}$ ano, à tarde.

- A JovemB15anos tem histórico de retenção no $2^{\circ}$ ano, em 2010, em outra escola da rede municipal de Cabedelo. Nessa escola, foi retida no $4^{\circ}$ ano, em 2013, com média baixa nas disciplinas de Geografia, Matemática e Artes; foi retida no $6^{\circ}$ ano, em 2016, à tarde, com média baixa em todas as disciplinas; no $6^{\circ}$ ano, foi retida no Ciclo III da EJA em 2017; em 2018, começou a estudar à tarde no $6^{\circ}$ ano e voltou para o turno da noite no Ciclo III, no $2^{\circ}$ semestre, e foi novamente retida em todas as disciplinas.

- O JovemC17anos foi retido em 2014, com médias baixas em todas as disciplinas, com $75 \%$ de frequência; foi retido em 2015, também com médias baixa em todas as disciplinas, exceto na disciplina de Inglês, com média final 8,8, e, na disciplina de Educação Física, com média final 8,7, no $6^{\circ}$ ano do ensino regular nessa escola.

- O entrevistado JovemD18anos começou a estudar nessa escola em 2015, no Ciclo II da EJA ( $4^{\circ}$ ano), no turno da noite; foi desistente em 2016.2, no Ciclo III ( $7^{\circ}$ ano); desistente em 2017, no $7^{\circ}$ ano, no turno da tarde, e retido em 2018, com médias baixas em todas as disciplinas, exceto em Ciências, com média final 8,4, e na disciplina Inglês, com média final 8,8 no Ciclo III ( $7^{\circ}$ ano), no turno da noite.

- E o estudante JovemE18anos foi retido no $4^{\circ}$ ano, em 2010, no turno da manhã, com médias baixas em todas as disciplinas, embora tivesse $83 \%$ de frequência; foi retido no $8^{\circ}$ ano, em 2015, no turno da tarde, em todas as disciplinas, exceto em Inglês, com a média final 7,0; desistiu em 2017 e em 2018, no Ciclo IV, na EJA, nessa mesma escola.

A questão que se coloca, portanto, a partir desses dados concretos, é a complexidade dessas histórias escolares, reativadas por trajetórias descontínuas na Educação Básica. E o esforço para superá-las é algo muito distante no horizonte dos jovens, pois eles são conduzidos 
precocemente para as turmas da noite pelo próprio sistema de ensino. O processo de construção da cultura da retenção/evasão, tratada como algo natural, é próxima à das análises de Teixeira (2018), ao alertar para o processo de migração das turmas regulares da Educação Básica para a Educação de Jovens e Adultos e para os impactos nos indicadores de rendimento e fluxo escolar. Pelo menos ao que parece, tal problemática se constitui como central e vai determinar, consequentemente, como advertem Jardilino e Araújo (2014), o fenômeno da juvenilização na EJA.

Quando isolamos, na análise, as categorias desistência e evasão escolar para a disciplina de Português, 71 foi o número de alunos que pararam de estudar. Para Matemática, o número dos que abandonaram a escola chega a 69. De um modo geral, o que esses números mostram? Para alguns pesquisadores que analisam o fenômeno da evasão e da desistência escolar, não temos mais como separar uma categoria da outra. Nos estudos de Jardilino e Araújo (2014) e Paiva (2016), evasão e infrequência são expressões com sentidos aproximados. Os alunos que desistiram já foram em algum momento evadidos da mesma escola. Este dado nos parece bastante próximo daqueles coletados na escola com cujos jovens realizamos entrevistas.

\subsection{Desempenho escolar}

Os dados referidos ao desempenho escolar - avaliação - e registrados nos Diários de Classe do Ciclo IV, anos 2017 e 2018, a partir dos saberes de Português, Matemática, Geografia, Ciências, História, Inglês e Artes, apontam que, dos 79 alunos, 37 do gênero masculino e 42 do feminino, temos uma média de 46,14 de jovens aprovados.

Por uma dimensão mais ampla sobre trajetórias escolares nos anos iniciais e finais do Ensino Fundamental e diante de falas mais consistentes que podem ser evidenciadas por meio de diferentes situações, alguns sujeitos percebem que a sua reprovação foi por causa do seu comportamento inadequado, por não conseguirem seguir as normas da escola,

Lembro pouco, fui retido no $3^{\circ}, 5^{\circ}$ e $6^{\circ}$ ano e o meu comportamento não era bom (JovemA17 anos).

Era difícil no começo porque eu não queria seguir as regras. [...]. Regras da escola. Farda, tudo; eu não queria cumprir horários (JovemB15anos).

Há também depoimentos relativos à negligência da própria escola e de professores, além de outros que enfrentam a situação vendo-a até como "normal".

[...] Não deixaram estudar à tarde porque eu tinha 14 anos no $4^{\circ}$ ano. Lá onde estudava eu não passei, os professores eram chatos e não gostavam de ensinar. Era difícil ter aula onde eu estudava (JovemD18anos).

Eu estudei aqui mesmo, foi normal (JovemE18anos). 
Veem-se "diferentes situações" denunciadas por esses fragmentos de narrativas e que sugerem a preservação de relações sociais no complexo jogo de correlação de forças entre o verdadeiro e o falso. No exercício de saber-poder, o discurso pedagógico vai engendrando uma certa consciência de si mesmo, segundo aponta Larrosa (2008, p. 70). Nessa constituição discursiva, parece-nos que o "outro" passa a ser não apenas o que incomoda na escola mas também o que carrega consigo, muitas vezes, estigmas, quando ele mesmo percebe e experimenta sentimentos de intolerância, de indisciplina, de exclusão etc.

Essa realidade produzida nas/pelas relações sociais impõe, sem dúvida, caminhos desafiadores aos modos como os jovens pobres experimentam uma condição juvenil e uma inserção social numa sociedade marcadamente excludente. Por essa via, e segundo sublinha Dayrell (2007, p. 1108), “Ao lado da sua condição juvenil (como jovens), alia-se a da pobreza, numa dupla condição que interfere diretamente na trajetória de vida e nas possibilidades e sentidos que assumem a vivência juvenil".

O JovemE18anos estuda na EJA desde 2015 e nunca foi aprovado. Para esse jovem, a sua experiência da reprovação é considerada "normal". Com o histórico de exclusão no ensino regular na idade e ano escolar considerados na faixa etária, qual o sentido para ele de aprender nas turmas da EJA? Essa percepção apenas reforça toda uma lógica de estigmas, de preconceitos, sobretudo, para os jovens investigados que precisam pensar no trabalho, num primeiro plano, e na escola como uma possibilidade de complementação de conteúdos formativos para o mercado de trabalho. São sucessivas repetências na escolaridade regular e que experimentaram, na contramão do direito à educação, contínuas situações de exclusão.

Numa dimensão mais específica, as questões levantadas junto aos jovens abordam temas que nos ajudam a refletir sobre outras adversidades por eles enfrentadas na escola. A primeira questão remete-nos à relação dos jovens com as disciplinas. No Ensino Fundamental regular, é possível identificar algumas percepções.

Era boa, mas não fazia as tarefas. Não gostava das disciplinas de Português e História (JovemA17anos).

Gostava de todas, mas não conseguia entender as aulas por causa da bagunça dos alunos, a turma ficava bagunçando e os professores colocavam os mais bagunceiros para fora da sala (JovemD18anos).

Por diferentes ângulos e embates, eles são “[...] constantemente 'expulsos' por professores e diretores sempre que estes passam a constituir qualquer tipo de 'problema' ou de 'ameaça' à normalização regulada pela ordem do poder" (PAIVA, 2016, p. 114). "Não fazia as tarefas", "a turma ficava bagunçando" e "os professores colocavam os mais bagunceiros para fora da sala" são enunciados que naturalizam a lógica do "dentro/fora" da escola. Entre os 
muros da escola, cria-se um consenso que todos aí estão para aprender e o tempo escolar é igual para todos. De fato, as desigualdades educacionais, como podemos observar na percepção desses jovens, não só refletem os paradoxos da escola em não saber como lidar com a dimensão social e cultural dos seus alunos como também apontam para a manutenção de um modelo anacrônico de escola. Isso evidencia uma situação que, na prática, se distancia do que deveria ser a função da escola: "um lugar efetivo de sistematização e de produção de saberes". Ou seja, "Os jovens são sujeitos de direitos, entre os quais o de ter acesso a saberes e conhecimentos socialmente produzidos. [...]”' (DAYRELL; NOGUEIRA; MIRANDA, 2011, p. 56).

Na EJA, essa vivência/percepção negativa com as disciplinas e os saberes docentes é percebida por alguns jovens como a ausência de diálogo com professores, pois os alunos são "treinados", condicionados, desde o Ensino Fundamental, a realizarem atividades de sala de aula pouco simétricas, no sentido em que elas não estabelecem relações fundamentais entre teoria (reflexão sobre a prática) e prática (modo de fazer) e, a partir destas relações, promoverem o seu oposto: processos de aprendizagem qualificadores, potentes. Nesse contexto e de acordo com a fala do JovemE18anos:

Normal, tem disciplina que o professor tem mais diálogo, e tem outras em que as aulas são bem chatinhas [...] o professor fala muito; gosto quando ele copia, porque a pessoa fica olhando e fazendo alguma coisa; tem professor que dialoga mais, tem professor que dá vontade de dormir. Agora tem os conteúdos que me chamam atenção dos Ciclos III e IV, eu percebi que às vezes são os mesmos assuntos e tarefas para os 2 Ciclos. Percebi, porque a minha esposa estuda aqui no Ciclo III, e no caderno dela tem a mesma tarefa que escrevo no meu caderno.

Esses desencontros pedagógicos aproximam-se do que Leão $(2007$, p. 77$)$ vai chamar de visão "escolocêntrica".

Segundo esse olhar, os jovens chegam à escola com disposições e hábitos que entram em conflito com o ambiente e a cultura da escola desenvolvidos em suas famílias de origem ou produzidos pela vivência na pobreza. Essa perspectiva separa também os professores dos espaços de encontro e diálogo com os jovens $[\ldots]$.

Ao serem reprovados por questões comportamentais, conversas em sala de aula, heterogeneidade na EJA, são classificados como alunos "sem futuro". Estereotipados na comunidade escolar como os "bagunceiros", desistentes, reprovados e evadidos, vão permanecendo na escola até que são transferidos para EJA. Nesse contexto, eles têm, ao mesmo tempo, seus direitos sociais e coletivos vilipendiados pelas formas de exclusão, produzidas na in/visibilidade pelo próprio sistema de ensino. Reconhecer seus direitos e desconstruir um modo de produção de um "enquadramento que não muda", segundo assinala Paiva (2017, p. 115), 
continua sendo um "alerta recorrente" para as instituições escolares que atendem aos sujeitos das classes populares.

É neste sentido que compreendemos como esse "enquadramento" vai se cristalizando. A trajetória escolar do JovemE18anos é ilustrativa e indica que a escola exerce uma função pouco fundamental em suas vidas. Tanto no Ensino Fundamental regular quanto nas turmas da EJA, os estudos constituem uma realidade cada vez mais distante. O referido jovem fala que, com menos de 15 anos, estudava à tarde e, por motivo de trabalho, desistiu da escola. Assim, ficou esperando completar a idade de 15 anos para estudar na EJA. É neste sentido que a noção de "tempo presente" é importante para pensarmos a relação da escola na vida dos jovens. A problemática da retenção e da evasão escolar, que funda a realidade dos alunos com trajetórias descontínuas escolares, é o reflexo da ausência do reconhecimento desses alunos como sujeitos de direitos.

\begin{abstract}
Essa relevância do tempo presente expressa-se, por um lado, nas relações educativas estabelecidas com os conhecimentos em sua aproximação com a realidade vivida, com a experiência; e, por outro lado, no acesso a uma renda que atenda à necessidade premente de maior autonomia reivindicada por esses jovens (DAYRELL; NOGUEIRA; MIRANDA, 2011, p. 56).
\end{abstract}

Entendemos que a escola, de um modo geral, lida com uma concepção monolítica sobre o que significa ser jovem - suas demandas, os territórios por onde eles transitam e buscam afirmar as suas identidades, suas culturas; seja no bairro onde moram, na escola noturna, ou antes, na escola diurna, já que estamos analisando a trajetória de jovens que migraram para o ensino noturno. O espaço escolar, portanto, não se constitui, em definitivo, no espaço para autocrítica, para questionar o lugar da escola sustentado, tantas vezes, no dizer de Sodré (2012, p. 247), com base em políticas públicas, “[...] geralmente vazadas na retórica das falsas prioridades, em que se ancora o modelo hiperburocratizado da educação [...]".

Sobre a distribuição do material escolar e em relação ao livro didático, todos afirmaram não o receber. O JovemE18anos enfatiza a ausência de mais estrutura, como a falta de professor de Inglês, por exemplo. E sobre o livro didático, ele afirma que, em 2018, ele "usava livro usado, mas tem livro novo e às vezes o professor utiliza o livro novo". No tocante ao professor substituto de Inglês e ao falar sobre como a prática docente acontece, o jovem afirma que ele "não ensina bem". Fica evidente aqui que estes aspectos apontam para uma clara percepção do referido aluno em relação às sucessivas dificuldades colocadas pela escola e por ele enfrentadas no Ensino Fundamental e nas turmas da EJA. Fica evidente, também, a reprodução das condições materiais (dimensão objetiva) impostas pela escola e pela condição social dos seus alunos (dimensão subjetiva). 
Nesta equação em que gravitam "desencantos, alegrias e resistências" por parte desse e dos outros jovens, as condições de permanência na escola mostram-se frágeis diante de uma realidade escolar que, em linhas gerais, é marcada pelas frágeis condições estruturais bem como diante da "[...] inexistência ou precariedade de material didático; currículo quase congelado pelos mecanismos de reprodução que multiplicam os fracassos escolares; alunos e professores extenuados pelas múltiplas exclusões de que são alvos”, como afirma Linhares (2004, p. 25 26). Nessas circunstâncias, alguns jovens relataram e atribuíram aspectos negativos no Ensino Fundamental na escola e hoje se encontram matriculados nas turmas da EJA.

Triste, mas já sabia que seria reprovado por causa do meu comportamento, não era bom. Era mau, bem mau [...] bagunçava muito na sala com outros colegas (JovemA17anos).

Senti um pouco ruim, até o meu padrasto esteve aqui na escola e eu faltava muito. Foi por falta de atenção minha também, eu sou culpado, me dediquei aos estudos depois para não ficar mais atrasado e na sala tinha muito alunos e tinha muita bagunça. Os professores só deixavam na sala quem queria estudar (JovemC17anos).

Essas duas situações nos sugerem refletir sobre a lógica do "destino previamente anunciado". A fala de culpabilização do JovemA17anos diz respeito à causa pela reprovação, quando ele atribui a si mesmo o "mau comportamento" como o efeito para não aprender os conteúdos escolares. O JovemC17anos, ao inserir em sua fala o discurso da culpabilização, busca rever seu comportamento no sentido de ser reconhecido como o aluno "comportado e disciplinado" requeridos, contraditoriamente, pela mesma escola que o reteve e o remeteu às turmas da EJA. Aqui reside a pertinência da pergunta sobre o lugar da escola nos projetos de vida dos jovens.

Há, em se falando do direito à educação, um sequestro de cidadania e que se expressa em várias estatísticas nas quais se associam baixa escolaridade e condição de vulnerabilidade. São os jovens do fracasso e que não demonstraram familiaridade com a cultura escolar. (DAYRELL; NOGUEIRA; MIRANDA, 2011, p. 19).

No contexto dessas turmas de EJA, identificamos apenas uma situação de um jovem entrevistado que não apresenta histórico de reprovação, desistência ou evasão. 04 alunos relataram o sentido inverso.

Foi por falta e desistência e depois eu pedi a diretora para estudar à tarde em 2018 e desisti [...] porque a minha idade não era boa para estar no meio dos meninos, a minha idade é muita avançada, a minha e da minha irmã (JovemA17anos).

Estudei à noite e voltei para tarde em 2018 e voltei nesse mesmo ano para noite [...] porque à tarde estava tendo muitas brigas e por causa da minha [...] idade. A minha idade é 
avançada e o meu tipo (físico) para série que estava fazendo à tarde, e porque à tarde só tem mais crianças (JovemB15anos).

Sim, por causa do trabalho eu desisti de estudar (JovemD18anos).

[...] Por causa do trabalho (JovemE18anos).

No conjunto dessas falas, os jovens narram suas trajetórias e percursos escolares. $\mathrm{O}$ JovemA17anos tem histórico de desistência e reprovação. E o JovemB15anos, trajetórias de reprovação. Os fragmentos dos jovens “A” e "B", respectivamente, “[...] para estar no meio dos meninos [...]" e "[...] a minha idade é avançada [...]" traduzem e deixam evidentes as dificuldades atravessadas e vividas por eles num contexto escolar muito distante das demandas e dos desejos peculiares a esses alunos. O tempo para aprender na idade e ano escolar correspondentes ao que prevê a atual LDB e demais dispositivos normativos é uma realidade distante para esses jovens que podem ter a escola como uma das trajetórias possíveis para superar condições de pobreza e para transpor o que historicamente lhes foi determinado. Eles não se veem nas turmas com idades diferentes das suas. Há, inclusive, elementos temporal e geracional postos no imaginário desses alunos, cujos elementos aglutinam para eles a representação de que, nesse contexto escolar, o "tempo já passou”. Eles não mais se percebem como crianças ou adolescentes, mas como jovens com demandas e desejos singulares.

\subsection{Escola e trabalho}

Para os jovens "D" e "E", a questão do trabalho é o rompimento com a continuação dos estudos. O jovem "D" tem histórico de reprovação e desistência e o "E" de desistência. O que nos chama a atenção nessa questão é que o jovem "E" evadiu-se da escola em função do trabalho numa padaria do seu bairro. No contexto da EJA, apenas os jovens "C $C$ " e "D" conciliam estudo e trabalho. A inserção precoce do jovem pobre no mercado de trabalho é marcada pela informalidade, pelo subemprego. O JovemC17anos afirmou que trabalha atualmente numa marcenaria, auxiliando na produção de móveis e sem vínculo formal de trabalho. O mesmo ocorre com o jovem " $D$ ”, que já tem histórico de evasão escolar no ensino fundamental regular em função do trabalho. Disse-nos o JovemD18anos que trabalha atualmente numa oficina de lava a jato. Vale ressaltar que o jovem "E" se encontra matriculado no Ensino Fundamental da EJA e que não trabalha. A questão da paternidade precoce o fez retomar os estudos em função da realidade do mercado de trabalho. Sobre esses aspectos, Jardilino e Araújo (2014, p. 186) levantam a seguinte questão:

O retorno à escola não é acompanhado de condições adequadas às suas necessidades de aprendizagem, se considerarmos que esses jovens adultos, que [sic] enfrentaram realidades de trabalho, família e, em algumas situações, 
maternidade ou paternidade precoces, desemprego, assumindo muitas vezes responsabilidades que são de uma pessoa adulta.

Assim, a insidiosa necessidade para os jovens pobres de buscar conciliar estudo e trabalho é um dado concreto recorrente. O sentido mais visível dessa produção é que ela guarda em si um recorte de classe. Muito embora tenhamos ações a partir da implementação de políticas públicas da juventude - incluindo aqui a Secretaria Nacional da Juventude, com seus programas direcionados aos jovens em situação de risco social, desde os idos 2003, quando da criação da referida Secretaria no primeiro mandato do Governo Lula -, e apesar de diversos resultados exitosos por partes desses programas, a lógica insidiosa não apenas pune os pobres como também sedimenta/cristaliza verdades em torno do direito à igualdade em uma sociedade marcadamente desigual como a brasileira. O que estamos afirmando aqui é que não abandonamos os sentidos do dualismo na educação brasileira. Os jovens pesquisados e suas respectivas narrativas confirmam o caráter dual presente nas formas de assujeitamento produzidas pelo sistema de ensino. Há, portanto, uma cultura do direito à educação e das ocupações laborais previamente determinadas dentro de uma sociedade de classes que produz sujeitos e realidades.

Nas questões Escolaridade a que pretende chegar e Seus projetos para o futuro, buscávamos compreender como o jovem vai experimentando os sentidos de ser-jovem, os processos de transição entre a adolescência e a vida adulta (MELUCCI, 1997). Observamos que eles afirmam que desejam concluir a educação básica. Apenas o jovem "B" informa que pretende chegar à universidade. Entre desafios e o desejo de "terminar tudo", nos parece que a escola, de uma certa forma, ainda produz um certo sentido para os jovens - ou seriam eles tolerantes frente à intolerância do sistema de ensino? Em relação a essa questão, Paiva (2016, p. 112-113) sugere investigações para se compreender o fenômeno da permanência escolar, ao nos dizer: "[...] muitos que se vão, muitos ficam, permanecem, não desistem de traçar seus percursos. E esta me parece a questão central, esgotadas as tentativas de entender a evasão como desafio às políticas públicas".

Apesar de, em sua trajetória escolar, verem-se tantas reprovações, desistências e evasão, sendo excluídos da sala de aula regular, os sujeitos ainda buscam a EJA, ou para ela são encaminhados pelo próprio sistema de ensino, pois desejam terminar os estudos; alguns desejam ter um curso superior. E quando indagados sobre seus projetos para o futuro e sobre o nível de escolaridade a que eles pretendem chegar, eles são mais cuidadosos em suas respostas; tudo é um pouco mais explicado. Os projetos confirmam o lugar em que eles buscam se afirmar no contexto em que vivem, marcado, sobremaneira, pela pobreza. São jovens que vivem situações socioeconômicas desfavoráveis. De alguma forma, percebê-los como protagonistas é 
buscar superar o cidadão de "segunda classe", como, historicamente, eles são percebidos. O JovemA17anos afirma que almeja "ter casa própria, ter família e ser policial”. O JovemC17anos diz que busca "terminar os meus estudos para ter um trabalho melhor, que ganhe mais e que seja digno". A escolaridade dos pais do jovem "C" revela o lugar social da família. Seu pai é analfabeto que hoje vive de aposentadoria; a mãe é doméstica, tendo estudado até a antiga $6^{\text {a }}$ série, hoje $7^{\circ}$ ano do Ensino Fundamental. Superar o lugar social de onde eles são oriundos passa, necessariamente, por uma escola que os acolha e que leve em consideração suas características e demandas postas por uma realidade em rápida transformação, especificamente, no mundo do trabalho. E como ultrapassar as trajetórias de fracasso escolar e ocupacional de seus pais? O jovem "D” deseja estudar informática. E assegura: “[...] o meu sonho é ser militar” (JovemD18anos).

A despeito do que eles poderiam propor à escola para evitar as sucessivas retenção e evasão, vejamos o que eles afirmam:

Eu não sei. Mandaria os alunos que não queriam estudar para outra escola. Ou separava em outra sala e deixava apenas os que queriam estudar (JovemA17anos).

Não sei. Depende do aluno (JovemB15anos).

Sugiro aulas de reforço para aqueles que têm mais dificuldades em aprender (JovemC17anos).

A escola tem que passar os alunos e os alunos têm que se esforçar para aprender e não desistir. Não depende só dos professores. Os alunos têm que estudar também (JovemD18anos).

Ter professores na escola (JovemE18anos).

O que estas falas evocam? Mesmo que apontem para diferentes alternativas, dão pistas de que o problema do fracasso escolar é também o fracasso da escola. Por esse ângulo, os jovens, cada um ao seu modo e na condição de alunos, deixam evidências legítimas de que eles são impelidos a essa posição e lugar social. As narrativas tecidas por suas trajetórias escolares e afirmadas entre "desencantos, alegrias e resistências" dão pistas de um cenário escolar em que os conceitos de democracia e cidadania são compreensões apartadas de seu cotidiano, já que estamos falando de processos educacionais produzidos no chão de uma escola pública. De fato, "Engendra-se um mecanismo perverso em que as desigualdades social e escolar se identificam como enigma: fracassam na escola porque são pobres, ou são pobres porque fracassam na escola?" (DAYRELL; NOGUEIRA; MIRANDA, 2011, p. 19). E do ponto de visto do direito de aprender, suas falas também dão pistas de como o seu direito à educação, aprender ao longo da vida, é subjugado nos processos de permanente tensão e visíveis 
reprovação, desistência e evasão, produzidos por espaços escolares pouco democratizantes e pouco sensíveis à própria dinâmica social brasileira, produtora de tantas ambiguidades.

\section{Considerações finais}

A pesquisa propõe discutir o lugar que a escola ocupa na vida dos jovens. Reconhecendo seus limites, é visível o distanciamento da instituição com relação aos jovens. Algumas variáveis nos ajudam a confirmar esse distanciamento. Neste sentido e diante das inúmeras questões que atravessam o chão da escola para jovens, e não podemos excluir os adultos e idosos da EJA, a retenção e a evasão escolar são dispositivos pedagógicos que, certamente, contribuem para o aumento das desigualdades sociais e educacionais.

Os dados das Fichas Individuais e dos Diários de Classe, consonantes às narrativas dos jovens participantes da pesquisa, confirmam que, para uma parcela dos jovens matriculados, o horizonte de oportunidades é muito distante, no sentido de que há um outro modo de produção de exclusão dentro do próprio direito à educação quando olhamos para os resultados analisados na presente investigação. A dinâmica convergente revela as mesmas fragilidades que sempre pautaram, não como regra geral, os espaços da escola pública, direcionados, sobretudo, para os sujeitos das classes populares.

O sentido da escola é retratado nas falas, as quais dão pistas, como um lugar construído com base no modelo anacrônico; o que está evidenciado, tanto no sentido das práticas docentes homogeneizantes, quanto nas aulas dos professores - estas consideradas pelos alunos, como cansativas. Considere-se ainda que, para os estudantes, esses mesmos professores são promotores da "instrumentalização" do conhecimento, fazendo uso de cópias de conteúdos, sem estabelecerem relações ou diálogos entre a teoria e o sujeito no processo de aprendizagem. Confirmando a informação acima, é importante destacar um outro aspecto referente a essas formas de sujeição: a ênfase dos entrevistados ao dizerem que seus professores repetem os mesmos conteúdos e atividades trabalhados no Ensino Fundamental regular nos Ciclos III e IV, sem respeito às diferenças de nível e às suas expectativas.

Estabelecendo algum paralelo com os estudos de Jardilino e Araújo (2014), Conceição (2015), Teixeira (2018) e Oliveira e Costa (2020), os jovens da nossa investigação despertam nossa atenção para as variáveis que, ao promoverem distanciamentos, colaboram para que eles sejam conduzidos compulsoriamente às turmas da EJA; ao mesmo tempo, também ampliam um pouco mais o arco de dificuldades e dilemas no campo da educação de adultos com o fenômeno da juvenilização produzido pelo próprio sistema de ensino, e que acaba gerando outras questões para a Educação de Jovens e Adultos que, acolhe os jovens, “[ [... mas vive o 
desafio da juvenilização e da luta contra a ideia de ser caracterizada como correção de fluxo" (TEIXEIRA, 2018, p. 33).

Por fim, pensar a Educação de Jovens e Adultos desvinculada da cultura da certificação, do aligeiramento e da suplência é um longo caminho, sem dúvida, a ser percorrido. Percebê-la como vinculada a políticas públicas educacionais é buscar inseri-la no debate do campo das lutas em torno do direito à educação - pública, laica e para todos. Há avanços como marcos e dispositivos legais no campo da educação - e, como identificamos nesta investigação, retrocessos que impedem a efetividade do direito de aprender ao longo da vida. Quando uma criança ou jovem tem o seu direito social à educação desrespeitado, em função das práticas burocráticas e pedagógico-didáticas de retenção e de evasão escolar, e é conduzido precocemente e compulsoriamente às turmas da EJA, torna-se urgente analisarmos os efeitos perversos que estamos fabricando para uma parcela pobre da população. Os jovens desta pesquisa foram marcados e sentenciados por essa estrutura histórica condicionante. Dizem que eles perderam o tempo de aprender. Na verdade, quando uma sociedade não partilha igualdades, quem perde somos todos nós, por insistirmos em manter espaços escolares áridos e inférteis, quando estes poderiam promover o caminho inverso: o do direito humano de aprender - em que o olhar da descoberta do outro e do lugar será sempre o tempo de recomeços; e a escola, um espaço inesgotável de possibilidades e descobertas.

\section{REFERÊNCIAS}

ABRAMO, Helena Wendel. Considerações sobre a tematização social da juventude no Brasil. Revista Brasileira de Educação, São Paulo, nº 5/6, p. 25-36, 1997.

BARDIN, Laurence. Análise de Conteúdo. Lisboa: Edições 70, 1977.

BAUMAN, Zygmunt. Sobre educação e juventude. Conversas com Riccardo Mazzeo. São Paulo: Zahar, 2013.

BRASIL. Constituição (1988). Constituição: República Federativa do Brasil. Brasília, DF: Senado Federal, 1988.

BRASIL. Lei no 9.394, de 20 de dezembro de 1996. Estabelece as Diretrizes e Bases da Educação Nacional. Diário Oficial da União, Brasília, DF, 1996.

BRASIL. Resolução $\mathrm{n}^{\circ}$ 3, de 15 de junho de 2010. Institui Diretrizes Operacionais para a Educação de Jovens e Adultos nos aspectos relativos à duração dos cursos e idade mínima para ingresso nos cursos de EJA; idade mínima e certificação nos exames de EJA; e Educação de Jovens e Adultos desenvolvida por meio da Educação a Distância e dá outras providências. Diário Oficial [da] República Federativa do Brasil, Brasília, DF, junho, 2010. Disponível em: <http://presidencia.gov.br>. Acesso em: 13/05/2019. 
CASTRO, Mary Garcia. Política pública por identidades e de ações afirmativas. In: NOVAES, Regina; VANNUCHI, Paulo. (Orgs.). Juventude e Sociedade. Trabalho, Educação, Cultura e Participação. São Paulo: Fundação Perseu Abramo, 2004.

CONCEIÇÃO, Letícia Carneiro da. "A alternativa para o menino indesejável”: vozes e sujeitos na biopolítica da juvenilização da EJA. Trabalho apresentado no GT 18 - Educação de Pessoas Jovens e Adultas. Anais da 37 ${ }^{\mathbf{a}}$ Reunião Nacional da ANPEd. Florianópolis, Outubro de 2015. ISSN: 2447-2808. Disponível em: http://www.anped.org.br/sites/default/files/trabalho-gt184629.pdf. Acesso em: 03/08/2019.

CRUZ, Claudemir Gomes da; MOREIRA, Evando Carlos. PRÁTICAS E REPRESENTAÇÕES DA EDUCAÇÃO FÍSICA ESCOLAR EM DIÁRIOS DE CLASSE EM SINOP-MT (1979-2009). J. Phys. Educ., Maringá, v. 27, e2705, 2016 . Disponível em http://www.scielo.br/scielo.php?script=sci_arttext\&pid=S2448-

24552016000100105\&lng=pt\&nrm=iso. Acesso em: 31/03/2021.

DAYRELL, Juarez. A escola "faz" as juventudes? Reflexões em torno da socialização juvenil. Educ. Soc., Campinas, vol. 28, n. 100 - Especial, p. 1105-1128, out. 2007. Acesso em: 17/08/ 2019.

DAYRELL; NOGUEIRA, Paulo Henrique de Queiroz.; MIRANDA, Shirley Aparecida de. Os jovens de 15 a 17 anos: características e especificidades educativas. In: Cadernos de Reflexões - Jovens de 15 a 17 anos no Ensino Fundamental. Brasília: Via comunicação, MEC/SEB, 2011.

FERNANDES, Rubem César. Segurança para viver: propostas para uma política de redução da violência entre adolescentes e jovens. In: NOVAES, Regina; VANNUCHI, Paulo. (Org.). Juventude e Sociedade. Trabalho, Educação, Cultura e Participação. São Paulo: Fundação Perseu Abramo, 2004.

GIL, Antonio Carlos. Como elaborar projetos de pesquisa. 4. ed. São Paulo: Atlas, 2002.

GROSBAUM, Marta Wolak; FALSARELLA, Ana Maria. Condição juvenil: juventude e ensino médio no Brasil. Cadernoscenpec, São Paulo, v. 6, nº 2, p. 291-315, jul./dez. 2016.

HADDAD, Sérgio. Educação de Jovens e Adultos, direito humano e desenvolvimento humano. In: CATELLI JR, Roberto. (Org.). Formação e práticas na educação de jovens e adultos. São Paulo: Ação Educativa, 2017.

JARDILINO, José Rubens Lima; ARAÚJO, Regina Magno Bonifácio de. (Org.). Educação de Jovens e Adultos. Sujeitos, saberes e práticas. São Paulo: Cortez, 2014.

LARROSA, Jorge. Tecnologias do Eu e Educação. In: SILVA, Tomaz Tadeu. (Org.). O sujeito da educação: estudos foucaultianos. 6. ed. Petrópolis/RJ: Vozes, 2008.

LEÃO, Geraldo Magela Pereira. Políticas de juventude e Educação de Jovens e Adultos: tecendo diálogos a partir dos sujeitos. In: SOARES, Leôncio; GIOVANETTI, Maria Amélia; GOMES, Nilma Lino. (Org.). Diálogos na educação de jovens e adultos. 2. ed. Belo Horizonte: Autêntica, 2007. 
LINHARES, Célia Frazão Soares. Trabalhadores sem trabalho e seus professores: um desafio para a formação docente. In: ALVES, Nilda. (Org.). Formação de professores: pensar e fazer. 8. ed. São Paulo: Cortez, 2004.

MELUCCI, Alberto. Juventude, tempo e movimentos sociais. Revista Brasileira de Educação, São Paulo, nº 5/6, p. 5-14, 1997.

OLIVEIRA, Maria da Conceição Cédro Vilas Bôas; COSTA, Maria dos Santos. A Juvenilização da Educação de Jovens e Adultos: Desafios e Possibilidades Curriculares. Revista Práxis Educacional, Vitória da Conquista - Bahia - Brasil, v. 16, n. 42, p. 48-77, out./dez. 2020.

PAIVA, Jane. Direito à educação: permanecer na escola é um problema público? In: CARMO, Gerson Tavares do. (Org.). Sentidos da permanência na educação: o anúncio de uma construção coletiva. Rio de Janeiro: Tempo Brasileiro, 2016.

SODRÉ, Muniz. Reinventando a educação. Diversidade, descolonização e redes. 2. ed. Petrópolis/RJ: 2012.

TEIXEIRA, A. A educação escolar no Brasil. In: PEREIRA, L.; FORACCHI, M. M. (Org.). Educação e Sociedade. São Paulo: Companhia Editora Nacional, 1977.

TEIXEIRA, Eliane de Oliveira. A "fabricação" do jovem da EJA: reflexões sobre juvenilização e diversidade étnico-racial. Educação em Debate, Fortaleza, ano 40, n 75 , p. 25-42, jan./abr. 2018.

WAISELFISZ, Julio Jacobo. Mapa da Violência 2011. Os jovens do Brasil. Brasília/DF: Instituto Sangari; Ministério da Justiça, 2011.

\section{SOBRE OS AUTORES:}

\section{Eduardo Antonio de Pontes Costa}

Doutorado em Educação pela Universidade Federal Fluminense. Professor Associado da Universidade Federal da Paraíba. Líder do Grupo de Pesquisa Psicologia Escolar, Formação e Infância: estudos sobre classes populares e educação pública. E-mail: eduapcosta@gmail.com (iD https://orcid.org/0000-0002-8072-1777

\section{Rosângela Lopes da Silva}

Especialista em Supervisão Escolar pela Universidade do Norte do Paraná. Pedagoga pela Universidade Federal da Paraíba. Membro do Grupo de Pesquisa Psicologia Escolar, Formação e Infância: estudos sobre classes populares e educação pública. E-mail: rosanerosangela1@gmail.com

(iD) https://orcid.org/0000-0001-5449-6951 